\title{
DIFFUSION WELDING OF STEEL TO TIN BRONZE THROUGH POROUS INTERLAYERS OF NICKEL AND COPPER
}

\author{
A.I. USTINOV, Yu.V. FALCHENKO, T.V. MELNICHENKO, L.V. PETRUSHINETS, \\ K.V. LYAPINA, A.E. SHISHKIN and V.P. GURIENKO \\ E.O. Paton Electric Welding Institute, NASU \\ 11 Bozhenko Str., 03680, Kiev, Ukraine. E-mail: office@paton.kiev.ua
}

\begin{abstract}
Friction assemblies based on steel and bronze are widely applied in many mechanical systems. Steel and bronze joints are produced by diffusion welding at temperatures of $750-850{ }^{\circ} \mathrm{C}$. Defect formation in the joint zone in a number of cases is associated with high welding temperature. The paper deals with the possibility of lowering diffusion welding temperature by interlayer application in the case of making permanent joints of steel (20Kh3MVF) and bronze (BrOSN 10-2-3). Porous nickel and copper foils, produced by vacuum deposition, were used as interlayers. It is shown that application of such porous interlayers allows welding temperature to be lowered to $660-700{ }^{\circ} \mathrm{C}$. Lowering of welding temperature prevents growth of liquation precipitates of tin and lead in the joint zone, that lowers the probability of defect formation. The thus produced joints are stable at short-time heating to $800-850{ }^{\circ} \mathrm{C}$, that allows later on performing heat treatment of steel as part of composite material to increase its strength properties. 13 Ref., 1 Table, 5 Figures.
\end{abstract}

Key words: bimetal joints, steel, bronze, porous interlayers, diffusion welding, welding modes, joint structure

Bimetal materials consisting of steel and tin bronze and produced by diffusion welding are widely applied in mechanical systems (friction assemblies). Such a composite structure of material provides a combination of high strength and low friction coefficient to the parts. Reliability and service life of parts with bimetal structure depends on the quality of joining steel and tin bronze components.

According to the data of [1], structure of tin bronze BrOSN 10-2-3 consists of $\alpha$-solid solution and inclusions of $\alpha+\mathrm{Cu}_{3} \mathrm{Sn}$ ( or $\alpha+\mathrm{Cu}_{31} \mathrm{Sn}_{8}$ ) eutectoid. Its composition further includes nickel and tin. Nickel added to bronze increases the eutectoid amount, but does not form any new phases, while being in solid solution. Lead, insoluble in copper, is present in the form of individual inclusions. Difficulties in welding steel and tin bronze alloyed by lead are associated with higher liquation susceptibility of bronze, bronze surface melting already at $760-780{ }^{\circ} \mathrm{C}$, because of lead presence, as well as the probability of development of Rebinder effect at copper penetration into steel intercrystalline space.

Known is the technology of tin bronze welding to steel in the mode of solid-liquid state at tem- peratures $T_{\mathrm{w}}=870-880{ }^{\circ} \mathrm{C}$ and soaking for $t_{\mathrm{w}}=$ $=15 \min [2]$.

Authors of [3] developed a technology to produce joints of bronze bushing with slide bearing body. This technology envisages bushing pressing into the steel body with subsequent burnishing that ensures running of localized plastic deformation on steel-bronze interface. Then diffusion welding is performed at $T_{\mathrm{w}}=750{ }^{\circ} \mathrm{C}, t_{\mathrm{w}}=30 \mathrm{~min}$.

Known are technologies of steel to bronze welding with application of copper and nickel interlayers or electroplated nickel coatings. So, for instance, in welding $40 \mathrm{Kh}$ steel to bronze BrOSN 10-2-3 it is recommended to weld a copper interlayer $(1 \mathrm{~mm}$ thick $)$ to steel at $T_{\mathrm{w}}=900{ }^{\circ} \mathrm{C}$, $P_{\mathrm{w}}=10 \mathrm{MPa}, t_{\mathrm{w}}=20 \mathrm{~min}$, and then to weld the assembly to bronze at $T_{\mathrm{w}}=750{ }^{\circ} \mathrm{C}, P_{\mathrm{w}}=5 \mathrm{MPa}$, $t_{\mathrm{w}}=10 \mathrm{~min}$, that allows producing welded joints with $229 \mathrm{MPa}$ pull strength [4].

Conducted analysis shows that steel and bronze joints are produced during diffusion welding at elevated temperatures that may promote increase of liquational inhomogeneities in bronze or liquid phase formation in the joint zone. This leads to lowering of joint strength and dependence of its quality on bronze initial state. Welding temperature lowering can be one of the ways to prevent development of negative processes. However, even in the case of activation of diffusion processes in the joint zone by simultaneous 
deformation of samples being welded at rolling, material joining cannot be achieved at temperature below $750{ }^{\circ} \mathrm{C}[5]$.

On the other hand, it was shown in a number of studies that application of interlayers, based on ductile materials, can promote softening of the conditions of producing permanent joints [6]. Porous materials can also be used as such interlayers [7]. Taking these results into account, the possibility of lowering the temperature of diffusion welding of steel and tin bronze through nickel and copper interlayers with porous structure was considered, and the features of microstructure formation in the joint zone were studied in this work.

Materials and methods of investigation. Vacuum diffusion welding of samples of 20Kh3MVF steel (further on steel) and tin bronze BrOSN 10-2-3 (further on bronze) was conducted by the procedure, described in [8]. Welding process parameters were as follows: $T_{\mathrm{w}}=600-800{ }^{\circ} \mathrm{C}, t_{\mathrm{w}}=$ $=5-20 \mathrm{~min}, P_{\mathrm{w}}=10-20 \mathrm{MPa}$, vacuum in the working chamber was kept on the level of $1.33 \cdot 10^{-3} \mathrm{~Pa}$.

Thin foils of nickel and copper were produced by electron beam vacuum deposition by the procedure described in detail in [9].

Analysis of structural characteristics of foil and welded joints was performed in scanning electron microscope CAMSCAN 4, fitted with energy dispersive analysis system Oxford INCA Energy 200 to determine the composition on flat samples. For this purpose transverse sections of foils and welded joints were prepared by a standard procedure using grinding-polishing equipment of Struers. Deformational behaviour of thin foils during heating under the conditions of continuous tensile loads was evaluated in a dylatometric system fitted with a special device [10]. Load magnitude was selected as $1 / 10$ of applied

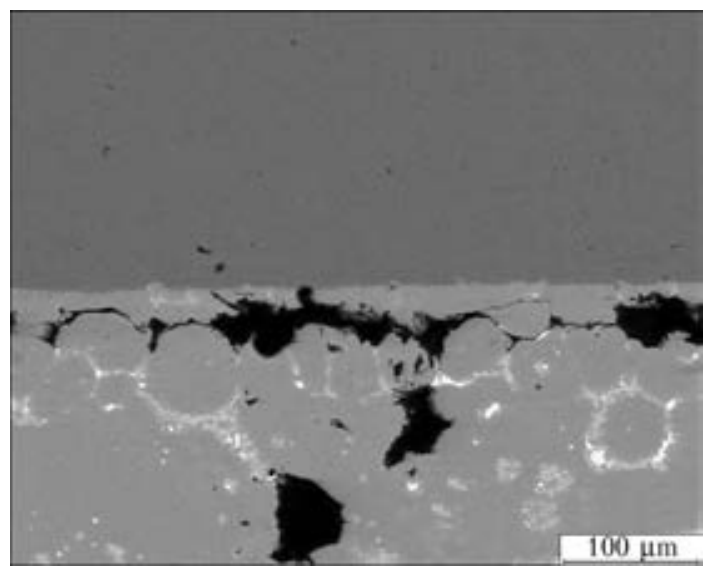

Figure 1. Microstructure of steel / bronze welded joint produced by diffusion welding at $T_{\mathrm{w}}=860{ }^{\circ} \mathrm{C}+$ quenching pressure that is equal to about $2-4 \mathrm{MPa}$ at diffusion welding under 20-40 MPa pressure.

Measurement of welded joint Vickers microhardness was performed with application of Polivarmet optical microscope, fitted with at attachment for microhardness measurement, at load on indenter of $0.098 \mathrm{~N}$.

Experimental results and their discussion. According to the data of [11], one of the methods to produce bimetal cylinder blocks of hydraulic machines is diffusion welding of parts from tin bronze and steel, which is performed at $870 \pm$ $\pm 10{ }^{\circ} \mathrm{C}$ for $50 \mathrm{~min}$ at constant pressure at assembly immersion into a salt bath. After completion of welding process, the parts are subjected to oil quenching that allows increasing steel hardness to required level.

Figure 1 gives a typical microstructure of a defective steel / bronze welded joint produced by diffusion welding at $T_{\mathrm{w}}=860{ }^{\circ} \mathrm{C}$ with subsequent quenching. High welding temperature leads to tin and lead liquation along grain boundaries with their subsequent evaporation that, alongside thermal stresses arsing at joint quenching from welding temperature, promotes appearance of ruptures and discontinuities in the weld zone. In [12] we have shown in the case of stainless steel that application of porous nickel foil allows lowering diffusion welding temperature.

Porous foil characterization. Porous nickel and copper foils produced by EB PVD process were used in the work. Figure 2 gives the characteristic cross-sectional microstructure of foils. It is seen that microstructure of as-deposited foils (Figure 2, $a, c$ ) is characterized by columnar structure of grains, the cross-section of which is equal to about 2-3 $\mu \mathrm{m}$, with elongated pores observed on their boundary, which run through the foil entire thickness.

In [12] in the case of vacuum condensates of nickel, it was shown that the conditions for producing such foils (low deposition temperature $T_{\mathrm{d}}<0.3 T_{\text {melt }}$, where $T_{\text {melt }}$ is the melting temperature of deposited metal) promote formation of structurally nonequilibrium state in them. Therefore, structural changes are observed in such foils at low heating, which are accompanied by the processes of pore coalescence and healing. These processes running results in changes in porous structure characteristics: a transition from open to closed porosity is observed, and pore shape changes from elongated to spherical one.

Investigations of deformational behaviour of porous nickel and copper foil at heating under the conditions of continuous tensile stresses (of the order of 2-4 MPa) showed that foil plastic 

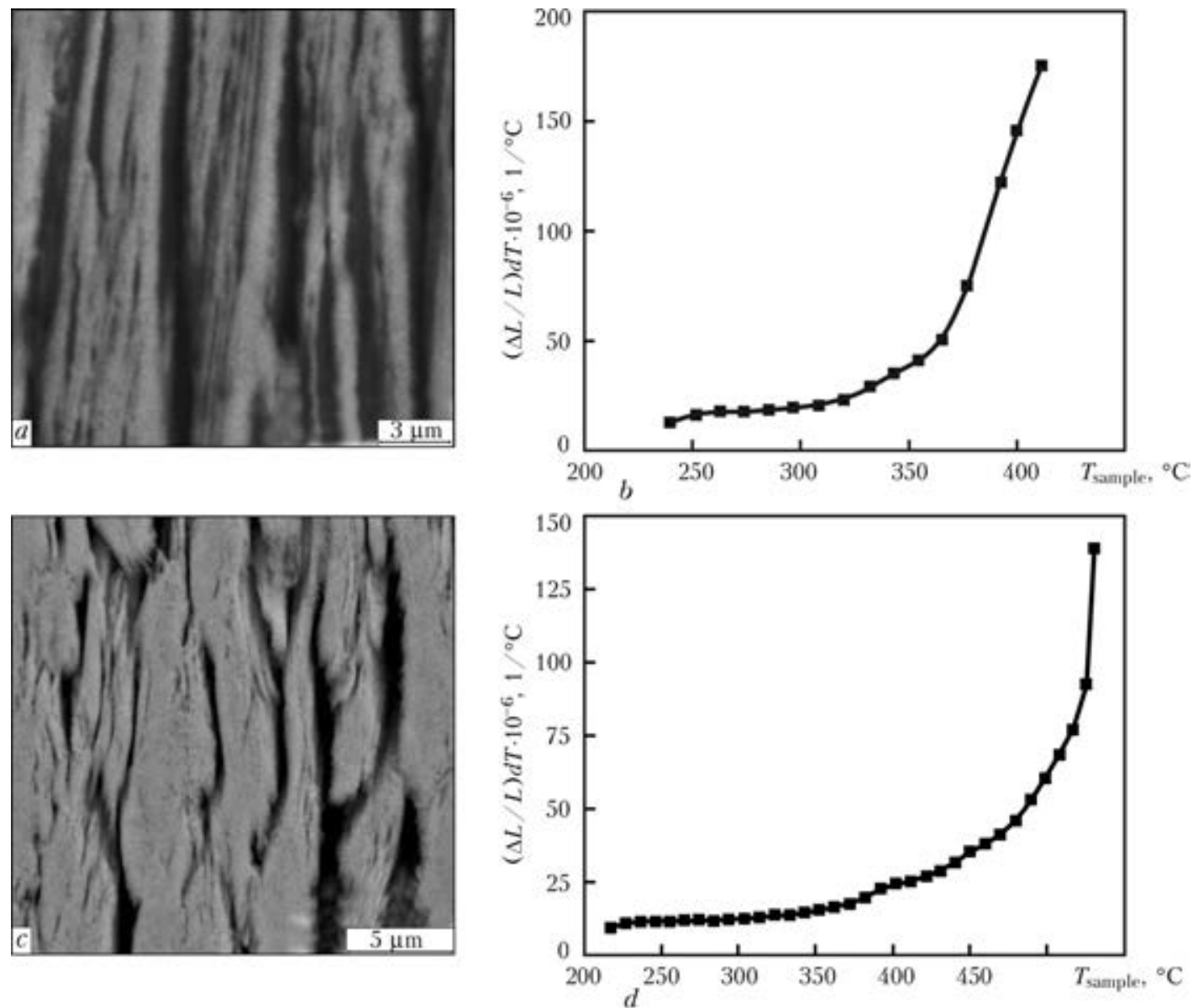

Figure 2. Microstructure and deformation rate of samples of porous foil based on copper with 30 vol.\% porosity $(a, b)$ and nickel with 25 vol.\% porosity $(c, d)$

flow rate non-monotonically depends on temperature. As is seen from Figure $2, b, d$, foil deformation rate at temperature increase varies as follows: up to 380 and $450{ }^{\circ} \mathrm{C}$ for copper and nickel foils, respectively, it remains on the level of metal coefficient of thermal expansion (tensile stresses below the foil yield point), and above the indicated temperatures their deformation rate rises abruptly, and acquires an exponential dependence. Such deformational behaviour of foil at heating is characteristic for materials at their transition into superplastic state, at which plastic deformation runs predominantly by the mechanism of intergranular slipping. In the case of pure metals, structural superplasticity is manifested at their heating above $0.5 T_{\text {melt }}$. Plastic deformation localizing along grain boundaries during superplastic flow of materials is accompanied by pore formation that, in its turn, promotes intergranular slipping [13]. This leads to an assumption that lower temperature of porous foil transition into superplastic state, compared to monolithic materials, can be due to presence of pores in them.

Proceeding from that, it can be assumed that interlayers with porous structure will promote development of plastic deformations in the joint zone at lower temperatures compared to those, at which running of plastic deformation of steel or bronze becomes possible, that is the prerequisite for establishing physical contact between the surfaces being joined and diffusion processes activation in them, and this, in its turn, will promote lowering of welding temperature. Moreover, welding temperature lowering can be influenced also by increased structural inhomogeneity of vacuum condensates.

Welded joint characteristics. Figure 3 shows the microstructures of steel/bronze welded joints produced through porous nickel foil with 25 vol. $\%$ porosity and $50 \mu \mathrm{m}$ thickness at different welding modes. It is seen (Figure $3, a$ ) that application of porous nickel interlayer ensures formation of steel $/$ bronze joint already at $T_{\mathrm{w}}=$ $=660{ }^{\circ} \mathrm{C}$. It should be noted that welding temperature is somewhat higher than that of porous nickel foil transition into the superplastic state $\left(450-500^{\circ} \mathrm{C}\right)$. Considering that formation of permanent joints in diffusion welding requires providing the conditions for intergrowing of grains between surfaces being welded, it can be assumed that at the temperature of interlayer transition 

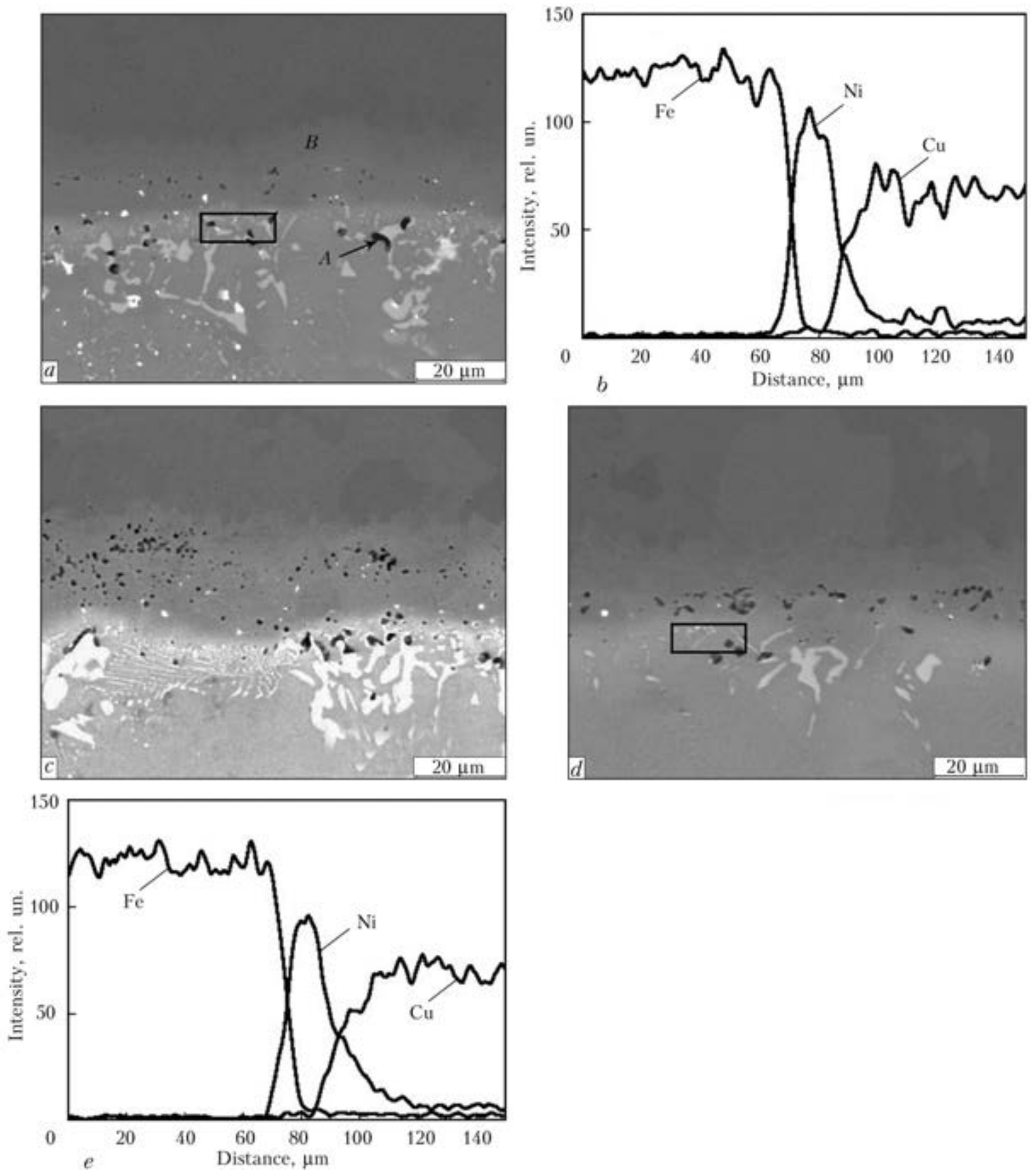

Figure 3. Microstructure of steel/bronze welded joint made by diffusion welding with application of porous nickel interlayer of $25 \mathrm{vol} \%$ porosity and $50 \mu \mathrm{m}$ thickness: $a-T_{\mathrm{w}}=660{ }^{\circ} \mathrm{C}, t_{\mathrm{w}}=30 \mathrm{~min} ; b-$ distribution of main components of materials in joint zone; $c-T_{\mathrm{w}}=700{ }^{\circ} \mathrm{C}, t_{\mathrm{w}}=5 \mathrm{~min} ; d-T_{\mathrm{w}}=700{ }^{\circ} \mathrm{C}, t_{\mathrm{w}}=20 \mathrm{~min} ; e-$ main component distribution in the joint zone, shown in Figure 3, $d$

into superplastic state, the rate of diffusion processes running is insufficient to provide these conditions. Results of studying the joint zone microstructure also provide evidence in favour of such a conclusion.

Phase contrast in the image of joint zone microstructure shows that interdiffusion of components of samples being welded and foil occurs at welding temperature. Diffusion-induced interaction of nickel foil with surfaces being welded results in foil becoming saturated with iron atoms from the steel side, and with copper atoms - from bronze side (Figure 3, b). A diffusion zone of inhomogeneous composition forms in the joint zone. More over, pores are observed in the diffusion zone.

Low welding temperature does not provide pore healing, either in nickel interlayer, or of pores in the HAZ, arising at coalescence of vacancies, which form as a result of unbalanced diffusion flows of copper atoms into nickel and those of nickel into bronze (Kirkendall effect). It should be noted that vacancy clusters (pores) form on the boundaries of copper alloy grains in 
Composition of joint zone near the interlayer-bronze interface

\begin{tabular}{|c|c|c|c|c|c|}
\hline \multirow{2}{*}{ Welding mode/Interlayer } & \multicolumn{5}{|c|}{$\begin{array}{c}\text { Composition of joint zone (designated by a rectangle in } \\
\text { microstructure image), wt.\% }\end{array}$} \\
\hline & $\mathrm{Fe}$ & $\mathrm{Ni}$ & $\mathrm{Cu}$ & Sn & $\mathrm{Pb}$ \\
\hline$T_{\mathrm{w}}=660{ }^{\circ} \mathrm{C}, t_{\mathrm{w}}=30 \mathrm{~min} / \mathrm{Ni}$ with $25 \mathrm{vol} . \%$ porosity, thickness of $50 \mu \mathrm{m}$ & 0.26 & 45.41 & 42.01 & 10.67 & 1.65 \\
\hline$T_{\mathrm{w}}=700{ }^{\circ} \mathrm{C}, t_{\mathrm{w}}=20 \mathrm{~min} / \mathrm{Ni}$ with $25 \mathrm{vol} . \%$ porosity, thickness of $50 \mu \mathrm{m}$ & 0.59 & 40.01 & 46.21 & 13.19 & - \\
\hline$T_{\mathrm{w}}=700{ }^{\circ} \mathrm{C}, t_{\mathrm{w}}=20 \mathrm{~min} / \mathrm{Ni}$ with $25 \mathrm{vol} . \%$ porosity, thickness of $20 \mu \mathrm{m}$ & 0.45 & 37.05 & 50.73 & 11.77 & - \\
\hline$T_{\mathrm{w}}=700{ }^{\circ} \mathrm{C}, t_{\mathrm{w}}=20 \mathrm{~min} / \mathrm{Cu}$ with 30 vol. $\%$ porosity, thickness of $30 \mu \mathrm{m}$ & 1.27 & 3.06 & 87.22 & 8.45 & - \\
\hline Bronze & - & 4.01 & 83.38 & 10.23 & 2.38 \\
\hline
\end{tabular}

the area of bronze/nickel foil interface (see Figure $3, a$, point $A$ ). Pores are absent in the area of diffusion zone from steel side (point $B$ ). Pore appearance in the area of bronze/nickel foil interface is attributable to the fact that nickel diffusion into bronze stimulates formation of eutectoid component. So, chemical analysis of this zone showed (the Table) that its nickel concentration is much higher that in bronze material. Eutectoid formation results in appearance of an additional vacancy inflow which ensures pore coalescence. At welding temperature increase up to $700{ }^{\circ} \mathrm{C}$, eutectoid volume fraction in bronze/nickel foil diffusion zone becomes greater (Figure 3,c). Here, the short welding time ( $5 \mathrm{~min})$ is insufficient for pore healing in the joint zone. It is seen that porosity of interlayer and diffusion zone in the area of bronze/nickel foil interface is more pronounced, compared to welding at $660{ }^{\circ} \mathrm{C}$ for $30 \mathrm{~min}$ (Figure $3, a, c$ ). At increase of soaking time at $700{ }^{\circ} \mathrm{C}$, porosity decreases both in the interlayer area, and in the area of bronze/nickel foil interface (Figure 3, $d)$. On the one hand, bronze / nickel foil diffusion zone becomes wider, while its nickel content per a unit of volume decreases that is indicative of
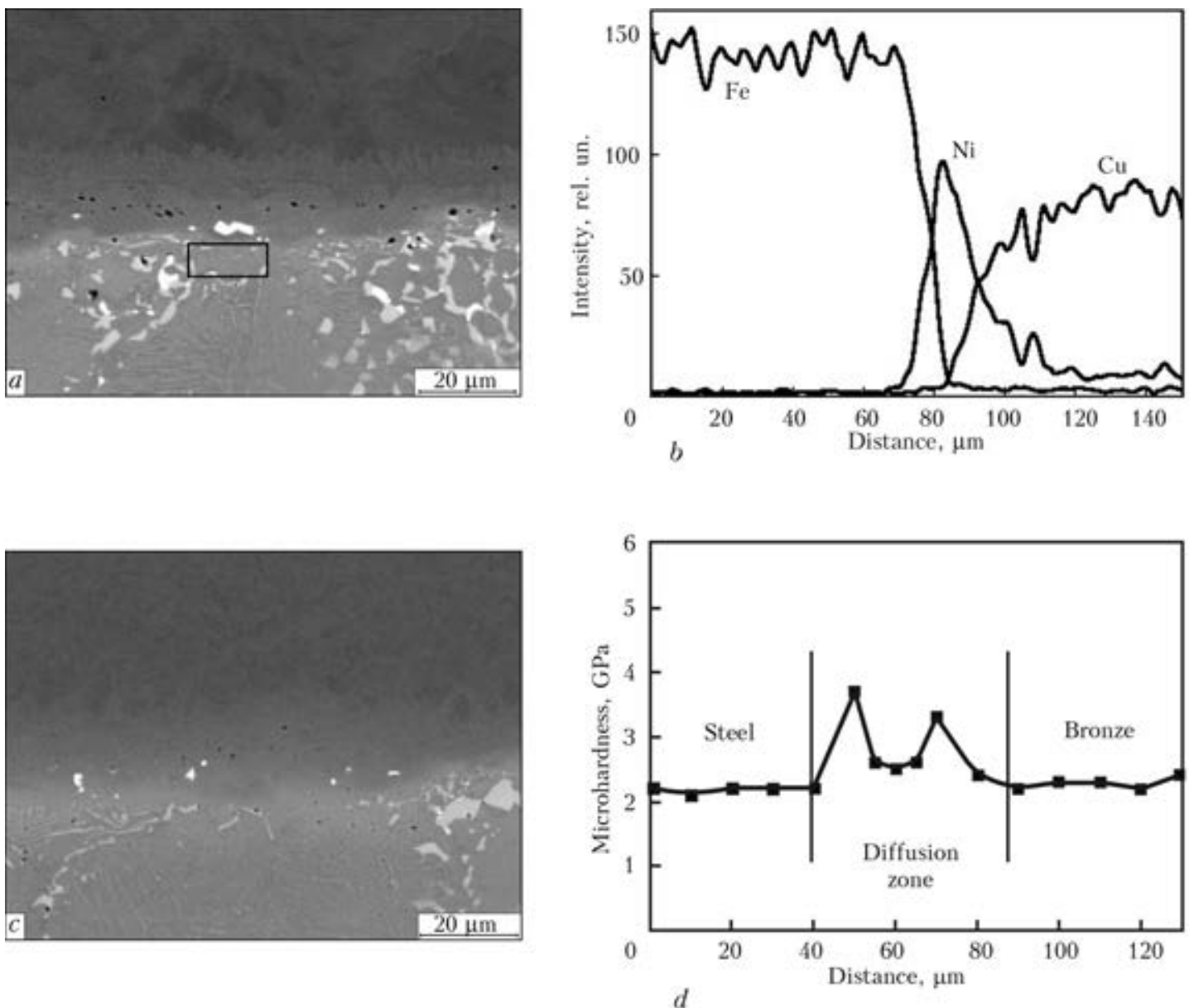

Figure 4. Microstructure of steel/bronze welded joint produced by diffusion welding with application of porous nickel interlayer at $T_{\mathrm{w}}=700{ }^{\circ} \mathrm{C}, t_{\mathrm{w}}=20 \mathrm{~min}: a-25 \mathrm{vol} \%$ porosity, $20 \mu \mathrm{m}$ thickness; $b-$ respective distribution of main elements in the butt area; $c-10$ vol.\% porosity, $20 \mu \mathrm{m}$ thickness; $d$ - microhardness distribution in the joint zone 
lowering of nickel concentration (see the Table), that leads to decrease of eutectoid volume fraction in the area of foil/bronze interface, and, therefore, vacancy inflow due to eutectoid transformation becomes smaller. On the other hand, longer soaking time ensures partial healing of pores, but it appears to be insufficient for complete elimination of porosity.

It is obvious that to eliminate residual porosity in the joint zone, it is necessary to decrease the volume fraction of pores and vacancies, associated with presence of porous foil interlayer in the butt. This can be solved in two ways: first,
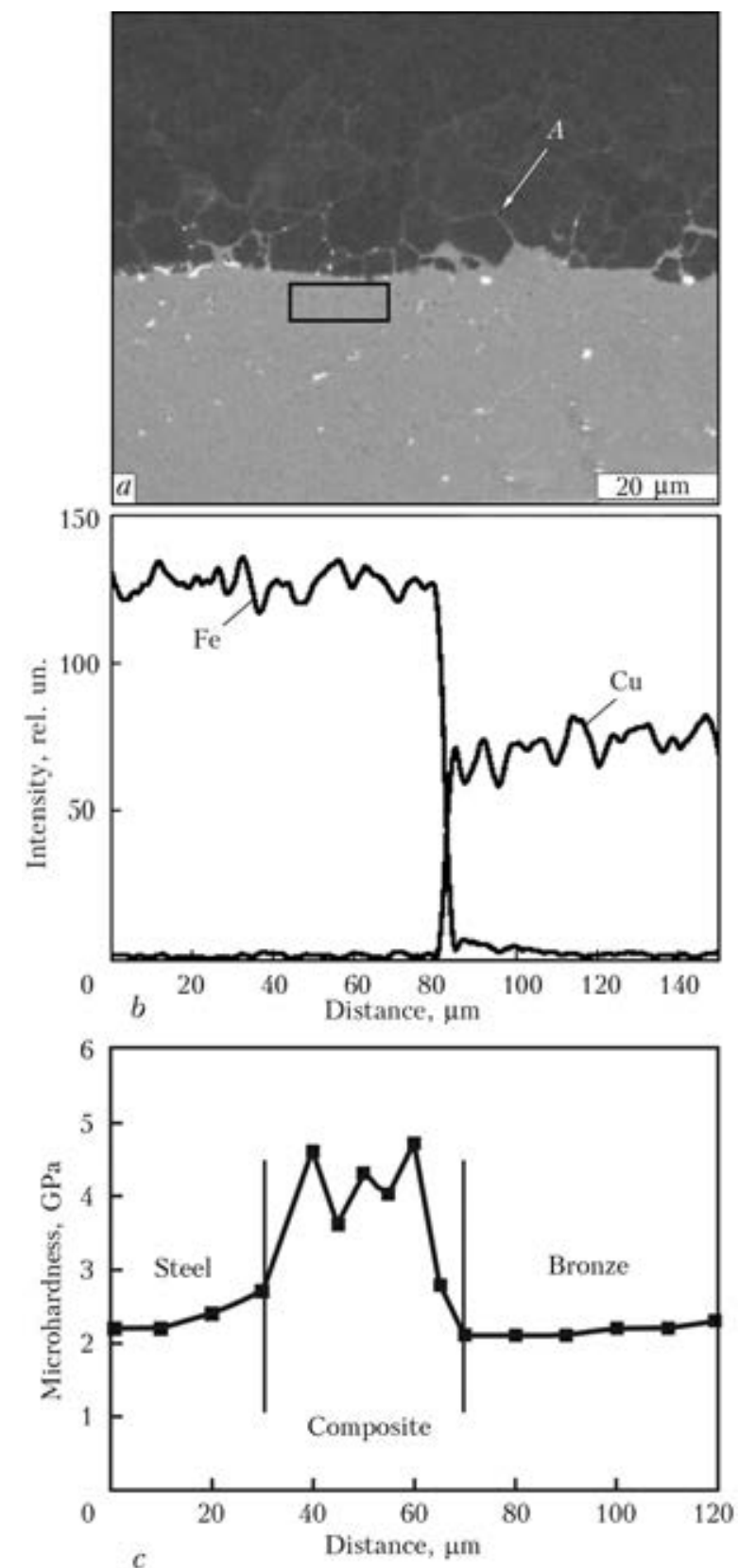

Figure 5. Microstructure of steel/bronze welded joint made by diffusion welding with application of porous copper interlayer with $30 \mathrm{vol} . \%$ porosity and $30 \mu \mathrm{m}$ thickness at $T_{\mathrm{w}}=$ $=700{ }^{\circ} \mathrm{C}, t_{\mathrm{w}}=20 \mathrm{~min}(a)$, distribution of main elements $(b)$ and microhardness $(c)$ in the joint zone by reducing foil thickness, and, second, by reducing its porosity.

Figure 4, $a$ shows the microstructure of steel / bronze welded joint, produced by diffusion welding at $T_{\mathrm{w}}=700{ }^{\circ} \mathrm{C}, t_{\mathrm{w}}=20 \mathrm{~min}$, using an interlayer of nickel foil with porosity of $25 \mathrm{vol} . \%$ and $20 \mu \mathrm{m}$ thickness. Application of thinner porous foil ensures reduction of residual nickel layer in the joint zone (Figure 4, b). Here, porosity in the foil area and in the diffusion zone from bronze side is reduced that can be the consequence of both reduction of eutectoid volume fraction, because of lowering of nickel concentration in this area (see the Table), and of pore healing. Application of interlayers with smaller porosity (of the order of $10 \mathrm{vol. \%}$ ) and $20 \mu \mathrm{m}$ thickness essentially lowers pore concentration both in the interlayer area, and near the nickel interlayer / bronze interface (Figure 4, c). Inhomogeneous composition of the diffusion zone affects microhardness distribution in the joint zone (Figure 4, $d$ ). It is seen that interdiffusion of the components of steel, bronze and interlayer leads to formation in the joint zone of material regions of higher microhardness than that in initial materials.

From the steel side diffusion interaction of iron and nickel leads to formation of particles of intermetallic compound $\mathrm{FeNi}_{3}$ that ensures precipitation hardening of material. Interdiffusion of copper and nickel leads to formation in the butt of material close to Monel high-strength alloy as to its composition. Obtained results give grounds to state that application of porous nickel interlayer in diffusion welding of steel and bronze intensifies the diffusion processes in the joint zone. On the one hand, this is promoted by establishing of good physical contact of the surfaces being welded due to superplastic behaviour of porous foil, and, on the other hand - relaxation of foil non-equilibrium state through pore coalescence and healing activates diffusion interaction of material components in the joint zone. Application of porous nickel foil allows lowering welding temperature that prevents appearance of the liquid phase on bronze surface and improves joint strength.

It is known [4] that one of the methods, preventing appearance of liquid phase on bronze surface during the welding process, is welding a thin copper interlayer to steel surface. In this connection, it is of interest to apply porous copper foil as interlayer in diffusion welding of steel and bronze. Figure 5, $a$ shows the microstructure of steel/bronze joint produced by diffusion welding with application of an interlayer of copper with 30 vol.\% porosity and $30 \mu \mathrm{m}$ thickness at 
$T_{\mathrm{w}}=700{ }^{\circ} \mathrm{C}, t_{\mathrm{w}}=20 \mathrm{~min}$. It is seen that the joint zone has no residual porosity. Absence of copperbased interlayer or clearcut interdiffusion zone in the joint zone is indicative of intensive diffusion of components of materials being joined and copper foil. Proceeding from element distribution in the joint zone (Figure 5, $b$ ) and data on chemical composition from bronze side (see the Table), it can be noted that in the area of copper interlayer location alloying element concentration is practically the same as in bronze, i.e. intensive redistribution of elements proceeds between porous copper interlayer and bronze during diffusion welding that promotes pore healing. At the same time, phase contrast in the image of joint microstructure (see Figure 5, $a$, point $A$ ) points to copper diffusion along steel grain boundaries.

Thus, performed studies lead to the conclusion that during welding diffusion interaction of porous copper interlayer on steel/copper interface is determined by grain-boundary diffusion of copper into steel, and that on the interface with bronze - by tin and nickel diffusion from bronze into copper. Diffusion redistribution of components during welding leads to formation in the joint zone of an interlayer of a steel-based composite with high microhardness. It can be assumed that such a change of mechanical properties in welded joint will promote localizing of plastic deformation under the impact of external load, chiefly, in bronze regions directly adjacent to steel. A smoother microhardness change in the area of steel/bronze joint produced with application of porous nickel interlayer will, probably, provide a more diffuse area of relaxation processes running at external loads.

\section{Conclusions}

1. Application of interlayers based on porous nickel and copper foil allows lowering the temperature of diffusion welding of steel/bronze to $660-700{ }^{\circ} \mathrm{C}$.

2. It is shown that at diffusion welding of steel and bronze through porous nickel foil the welded joint structure forms from the steel side by interdiffusion of nickel and iron atoms, and from bronze side - by that of nickel and copper atoms that leads to formation of material interlayers of higher microhardness in the butt area.

3. Structure of steel/bronze welded joint, made through porous copper interlayer forms by grain boundary diffusion of copper atoms into steel and by nickel and tin atoms diffusion into copper that promotes formation of a composite with higher microhardness in the joint zone.

1. Kazakov, N.F. (1976) Diffusion welding of materials. Moscow: Metallurgiya.

2. Malevsky, Yu.B., Nesmikh, V.S. (1981) Pressure welding of bronze with steel. Moscow: Metallurgiya.

3. Potekhin, B.A., Izmajlov, D.K. (2008) Peculiarities of vacuum diffusion welding without application of external pressure. Svarochn. Proizvodstvo, 2, 8-13.

4. Kazakov, N.F. (1981) Diffusion welding of materials: Refer. Book. Moscow: Mashinostroenie.

5. Charukhina, K.E., Golovanenko, S.A., Masterov, V.E. et al. (1970) Bimetallic joints. Moscow: Metallurgiya.

6. Ustinov, A., Falchenko, Y., Melnichenko, T. et al. (2013) Diffusion welding of aluminium alloy strengthened by $\mathrm{Al}_{2} \mathrm{O}_{3}$ particles through an $\mathrm{Al} / \mathrm{Cu}$ multilayer foil. J. Materials Proc. Techn., 213(4), 543-552.

7. Lyushinsky, A.V. (2011) Application of nanopowders of metals in diffusion welding of dissimilar materials. The Paton Welding J., 5, 31-34.

8. Kharchenko, G.K., Ustinov, A.I., Falchenko, Yu.V. et al. (2011) Diffusion bonding of $\gamma$-TiAl base alloy in vacuum by using nanolayered interlayers. Ibid., 3, $2-6$.

9. Ustinov, A.I., Lyapina, K.V., Melnichenko, T.V. (2005) Regularities of stainless steel porous structure formation during its deposition from vapor phase in presence of sodium chloride vapors. Advances in Electrometallurgy, 4, 19-24.

10. Ustinov, A.I., Matvienko, Ya.I., Polishchuk, S.S. et al. (2009) Investigation of phase transformations and plastic deformation at continuous heating of $\mathrm{Al} / \mathrm{Cu}$ multilayer foil. The Paton Welding J., 10, 23-27.

11. Vajvod, N.I., Bykov, G.M. (1982) Diffusion welding in production of cylinder blocks of axial-plunger pumps. Svarochn. Proizvodstvo, 3, 32-33.

12. Ustinov, A.I., Falchenko, Yu.V., Melnichenko, T.V. et al. (2015) Vacuum diffusion welding of stainless steel through porous nickel interlayers. The Paton Welding J., 7, 3-9.

13. Kuznetsova, R.I., Bryukhovetsky, V.V., Pojda, V.P. (1995) Mechanisms of development of grain-boundary pores and local deformation heterogeneity under conditions of superplastic flow. Metallofizika $i$ Nov. Tekhnologii, 17(8), 64-72. 